\title{
Uso de cinza de olaria e composto orgânico de macrófita aquática na recuperação de solos degradados: avaliação de metais pesados
}

\author{
Use of pottery ash and organic compound of aquatic macrophyte in degraded \\ soil recovery: evaluation of heavy metals
}

\author{
Hiara Ruth da Silva Camara Gaudencio $\left.{ }^{1}{ }^{*}\right)$ \\ Elís Regina Costa de Morais ${ }^{2}$ \\ Celsemy Eleutério Maia ${ }^{3}$ \\ Maria Valdete da Costa ${ }^{4}$ \\ Henrique Campos Nogueira ${ }^{5}$
}

\section{Resumo}

A intensificação da atividade humana para fins econômicos tem ocasionado impactos ambientais significativos, como a supressão vegetal e consequentemente o empobrecimento do solo. Nesse sentido, esta pesquisa objetivou avaliar o uso de cinza de olaria e composto orgânico de macrófita aquática na recuperação de solos degradados. Assim, o experimento foi conduzido com delineamento experimental em esquema fatorial $5 \times 5$, sendo cinco doses do composto de aguapé e cinco doses de cinza com três repetições, onde as doses de cinza corresponderam à $0,1,3,5$ e 10\% do volume de cada vaso e às de composto de aguapé à 0,5,10,20 e 30\%. Após a mistura da composição solo, composto e cinza de cada tratamento, esta foi colocada em vasos, incubados 20 dias, em seguida realizado o transplantio das mudas de Jucá (Libidibia ferrea). Por ocasião da coleta, as mudas foram cortadas ao nível do solo, secas em estufa de circulação forçada de ar a $70^{\circ} \mathrm{C}$ até peso constante, pesadas, trituradas em moinho para obtenção da matéria seca da parte aérea (MSPA) e posteriormente foram mineralizadas por digestão nítrica. Nos extratos foram determinados os teores totais de $\mathrm{Fe}, \mathrm{Zn}, \mathrm{Mn}, \mathrm{Cu}$, $\mathrm{Cd}$ e $\mathrm{Pb}$. Após a retirada das mudas, o solo de cada vaso foi seco ao ar, homogeneizado e quantificado os teores de $\mathrm{Fe}, \mathrm{Zn}, \mathrm{Mn}, \mathrm{Cu}, \mathrm{Cd}$ e $\mathrm{Pb}$. A adição das doses de cinza e o

1 Mes.; Ambiente, tecnologia e sociedade; Universidade Federal Rural do Semi-Árido,UFERSA, Brasil; Atuaprincipalmente na Linha de Pesquisa “Tecnologias Sustentáveis e Recursos Naturais do Semiárido”; Endereço: Av. Francisco Mota, 572. Bairro Costa e Silva. Mossoró-RN. CEP: 59.625-900; E-Mail: hiararuth@gmail.com (*) Autor para correspondências

2 Da.; Recursos Naturais. Universidade Federal de Capina Grande, UFCG, Brasil; Professor Associado I da Universidade Federal Rural do Semi-Árido, Prestação de Serviço do Fundação Guimarães Duque, Revisor de periódico da Revista Brasileira de Agricultura Irrigada e Revisor de periódico da Revista Brasileira de Engenharia Agrícola e Ambiental; Endereçp: Universidade Federal Rural do Semi-Árido. Av. Francisco Mota, (BR 110 - Km 47 ), Presidente Costa e Silva. CEP: 59625-900 - Mossoro, RN - Brasil E-Mail: elisregina@ufersa.edu.br

3 Dr.; Recursos Naturais. Universidade Federal de Campina Grande, UFCG, Brasil; Professor Associado da Universidade Federal Rural do Semi Árido; Endereço: Universidade Federal Rural do Semi Árido, Departamento de Ciências Ambientais. BR 110, km 47, Costa e Silva. CEP: 59625900 - Mossoró, RN - Brasil E-Mail: celsemy@ufersa.edu.br

4 Doutoranda; MANEJO DE SOLO E ÁGUA; Universidade Federal Rural do Semi-Árido, UFERSA, Brasil; Efetivo da Universidade Federal Rural do Semi-Árido; Endereço: Universidade Federal Rural do Semi-Árido, Conselho Universitário da UFERSA. Av. Francisco Mota, 572, Costa e Silva. CEP: 59625900 - Mossoró, RN - Brasil; E-Mail: mariavaldete@ufersa.edu.br

5 Mestrando; Fitotecnia; Universidade Federal Rural do Semi-Árido, UFERSA, Brasil; Membro do Projeto de Pesquisa Externo: Desenvolvimento de Um Modelo de Implantação de Tecnologias de Convivência com o Semiárido, da Universidade Federal Rural do Semi-Árido; Endereço: Av. Francisco Mota, 572. Bairro Costa e Silva. Mossoró-RN. CEP: 59.625-900; E-Mail: henriquecn123@gmail.com

\begin{tabular}{llllll}
\hline Ambiência & Guarapuava (PR) & v.14 n.2 & p. 356-369 & Maio/Ago 2018 & ISSN $1808-0251$
\end{tabular}


composto contribuíram para o aumento do $\mathrm{pH}$, que consequentemente influenciou na absorção dos metais pesados pelas mudas.

Palavras-chave: Recuperação de Áreas Degradadas; Aguapé; Bioma Caatinga; Libidibia ferrea.

\section{Abstract}

The intensification of human activity for economic purposes has caused significant environmental impacts, for example, the suppression of vegetation and soil impoverishment. In this sense, this research aimed to evaluate the use of pottery ash and organic macrophyte compound in the recovery of degraded soils. Thus, the experiment was conducted with experimental design in factorial arrangement of $5 \times 5$, being five doses of the compound of water hyacinth and five doses of ash with three replications, where the volume of ash doses corresponded to $0,1,3,5$ and $10 \%$ of the volume of each vessel and the water hyacinth compound at 0, 5, 10, 20 and 30\%. After mixing the composition of soil, compound and gray equivalent to each treatment, these were placed in vessels, incubated for 20 days and then held the transplanting of Jucá seedlings (Libidibia ferrea). On the occasion of collection, the plants were cut at ground level, dry in forced-air oven at $70^{\circ} \mathrm{C}$ to constant weight, weighed, crushed in a grinder to obtain the dry matter of shoot (MSPA) and were subsequently mineralized by nitric digestion. In the extracts were determined the total content of $\mathrm{Fe}, \mathrm{Zn}, \mathrm{Mn}, \mathrm{Cu}, \mathrm{Cd}$ and $\mathrm{Pb}$. After removal of the plants, the soil in each vessel was air dried, homogenised and a sample was removed for performing analysis of $\mathrm{Fe}, \mathrm{Zn}, \mathrm{Mn}, \mathrm{Cu}, \mathrm{Cd}$ and $\mathrm{Pb}$. The addition of ash and compound doses contributed to the increase in $\mathrm{pH}$, which consequently influenced the absorption of heavy metals by plants.

Keywords: Recovery of Degraded Areas; Water hyacinth; Caatinga Biome; Libidibia ferrea.

\section{Introdução}

Nas últimas décadas, ações antrópicas vêm ocasionando sérias consequências ao meio ambiente, possivelmente porque o sistema econômico vigente demanda uma produção em larga escala e, consequentemente, maior uso dos recursos naturais. Porém, a preocupação em se realizar um manejo adequado desses recursos ainda é escassa. É nesse contexto que se insere a necessidade de apoio a técnicas e tecnologias que viabilizem a fertilização orgânica do solo, a fim de que sua vida útil seja prolongada, diminuindo a necessidade de busca de novas áreas de cultivo num curto período de tempo, fato que ocasiona cada vez mais desmatamento das florestas, especialmente no Brasil.

A Recuperação de Áreas Degradadas pode ser entendida como um "conjunto de ações idealizadas e executadas por especialistas das diferentes áreas do conhecimento humano, que visam proporcionar o restabelecimento das condições de equilíbrio e sustentabilidade existentes anteriormente em um sistema natural" (TAVARES et al.,2008). Diversas são as técnicas utilizadas para se reestabelecer as condições de equilíbrio e sustentabilidade num determinado ambiente. Malavolta et al. (1989) e Calgaro et al. (2008), por exemplo, afirmam que a incorporação do 
composto orgânico proveniente de macrófita aquática (Eichhornia crassipes) vem se mostrando, por meio de alguns estudos sobre suas propriedades e utilizações, como um recurso eficiente na fertilização do solo, na despoluição de corpos d'água, entre outras destinações.

Da mesma forma, a cinza apresenta-se como uma alternativa viável na fertilização de solos degradados. Estudos apontam que a queima de lenha utilizada nas indústrias dos mais diversos setores, em especial da indústria de cerâmica, tem disponibilizado a cinza de seus fornos para pesquisas, visando dar a este resíduo uma nova destinação, que não seja seu lançamento ao solo ou em corpos d'água sem qualquer tratamento, aumentando os níveis de contaminação onde estão situadas essas indústrias (MAEDA; SILVA; MAGALHÃES, 2007; BONFIM-SILVA et al., 2013).

Nesse contexto, o uso das cinzas como fonte de nutrientes para os solos, minimiza os impactos ambientais negativos em todo seu processo produtivo, desde a extração de espécies arbóreas da Caatinga, retirada de argila das áreas de leito de rios, queima de lenha nativa, até a obtenção do produto final que gera a cinza e lançam poluentes, na forma de gases na atmosfera. Porém, com a instituição do Decreto No 14.338/1999, que atesta a competência do Instituto de Desenvolvimento Sustentável e Meio Ambiente do Rio Grande do Norte (IDEMA) para concessão de licenças a empreendimentos considerados causadores de poluição, as indústrias cerâmicas passaram a ser licenciadas (IDEMA, 2014).

No entanto, disposição final ambientalmente adequada da cinza gerada ao final do processo não é cobrada por essa instituição. Em outras palavras, a cinza ainda não foi incorporada ao processo de licenciamento, deixando esse resíduo que pode assorear corpos d'água (que estão situados próximos a algumas indústrias), ocasionando problemas ambientais cujas consequências podem ser agravadas caso essa prática persista. Com base nessa preocupação, procurou-se analisar pesquisas que já fizeram uso da cinza para que, a partir do estudo das suas propriedades e nutrientes, fosse possível seu reaproveitamento como fertilizante em diversas culturas.

De maneira semelhante ocorre com a macrófita aquática (E. crassipes). Esta planta aparece nos corpos d'água que apresentam níveis significativos de poluição por presença de matéria orgânica. A partir de sua instalação, passam a despoluir os rios, retirando deles os nutrientes necessários ao seu desenvolvimento. Encontrando esse ambiente propício à sua manutenção, acabam se proliferando de maneira muito rápida. É a partir dessa realidade que as plantas de aguapé representam um problema. Essa rápida reprodução ocasiona também uma acelerada decomposição de sua biomassa, necessitando da retirada das plantas do rio.

Assim, faz-se necessária uma utilização racional desse recurso, uma vez que apenas sua retirada do rio e o lançamento em local inadequado continuarão ocasionando poluição. Portanto, fez-se também a análise de pesquisas sobre o uso da macrófita aquática na geração de composto orgânico e respectiva aplicação em diferentes culturas, devido à presença de nutrientes importantes em sua biomassa.

Com base nesses fatos, torna-se importante a realização de uma pesquisa que busque avaliar o uso de cinza de olaria e composto orgânico de macrófita aquática (E. crassipes) na Recuperação de Áreas Degradadas. Isso porque essa prática visará a preservação da Caatinga, através do cultivo de espécies nativas deste bioma, a fim de melhorar a qualidade de vida das pessoas que nele residem. Assim, essa pesquisa teve como objetivo avaliar o uso de cinzas provenientes da indústria da cerâmica e do composto orgânico proveniente de macrófitas aquáticas na recuperação de solos degradados. 


\section{Material e Métodos}

\section{Local de Estudo}

O município de Mossoró está localizado na mesorregião Oeste Potiguar e na microrregião Mossoró, abrangendo uma área de $2.099 \mathrm{~km}^{2}$, a qual equivale a cerca de $4 \%$ da superfície do estado do Rio Grande do Norte. Esta área possui clima muito quente e semiárido e nela encontra-se uma biodiversidade de espécies, características do bioma Caatinga (IBGE, 2010). Além disso, apresenta chuvas concentradas entre os meses de fevereiro a abril, com precipitação em torno de $700 \mathrm{~mm}$ anuais (IBGE, 2010). No tocante aos recursos hídricos, a cidade está totalmente inserida na Bacia Hidrográfica do rio Apodi-Mossoró, o qual margeia a cidade no sentido sudoestenordeste (GRIGIO; DIODATO, 2011).

O trecho do rio Mossoró que abrange a faixa urbana da cidade vai da barragem de Genésio, sob a ponte da BR-304, até a barragem de Passagem de Pedras. Nessa área, o rio sofreu intervenções para a construção de dois canais artificiais. Esses canais, associados a um sistema de quatro barragens sucessivas, no trecho principal, controlam a vazão das águas durante todo o ano, principalmente nas épocas de cheias.

\section{Etapas da Pesquisa}

\section{Obtenção dos aguapés e composto de aguapé}

Os aguapés foram coletados na área urbana do município de Mossoró/RN, mais precisamente nas proximidades da barragem de baixo, no bairro Barrocas. Após a coleta, as plantas foram distribuídas em bancadas dentro de uma estufa, para facilitar a desidratação. Dessas plantas, aleatoriamente foi retirada uma amostra e conduzida ao Laboratório de Biotecnologia, da Universidade Federal Rural do Semi-Árido (UFERSA), que foi cuidadosamente lavada com água destilada, em seguida seccionada em folha, caule e raiz, acondicionada separadamente em sacos de papel devidamente identificados e levado para secagem na estufa a $70^{\circ}$ até peso constante, em seguida pesada para obtenção do peso seco. A matéria seca foi triturada em moinho tipo Wiley e mineralizada por digestão nítrica. Nos extratos foram quantificados os teores totais de $\mathrm{Fe}, \mathrm{Zn}$, $\mathrm{Mn}, \mathrm{Cu}, \mathrm{Cd}$ e Pb (Tabela 1), seguindo metodologia da EMBRAPA (2011).

Após totalmente secas, as raízes das plantas de aguapé foram retiradas, e a parte aérea utilizada para preparar o composto. $\mathrm{O}$ composto foi montado em caixas plásticas vazadas, deixando-se espaço para posterior revolvimento, recebeu água diariamente e era revolvido de uma a duas vezes por semana. As caixas foram acondicionadas à sombra de uma árvore e a parte superior protegida por tela de nylon. Além disso, eram suspensas do chão com ajuda de tijolos, a fim de que nenhum tipo de material proveniente do ambiente externo pudesse ser incorporado. Após o período de maturação, foram quantificados os teores totais de $\mathrm{Fe}, \mathrm{Zn}, \mathrm{Mn}, \mathrm{Cu}, \mathrm{Cd}$ e $\mathrm{Pb}$ (Tabela 1), seguindo metodologia da EMBRAPA (2011). 


\begin{tabular}{|c|c|c|c|c|c|c|c|}
\hline & $\mathrm{pH}$ & $\mathrm{Fe}$ & Zn & Mn & $\mathbf{C u}$ & $\mathrm{Cd}$ & $\mathbf{P b}$ \\
\hline Aguapés & - & 410,00 & 124,52 & 13,05 & 33,00 & 0,00 & 20,50 \\
\hline Composto & 8,15 & 1,35 & 0,00 & 8,70 & 0,0005 & 0,00 & 0,21 \\
\hline Cinza & 12,85 & 195,00 & 0,00 & 2,19 & 0,24 & 0,00 & 33,50 \\
\hline Solo & 6,20 & 5,50 & 0,00 & 1,23 & 0,0043 & 0,00 & 0,48 \\
\hline
\end{tabular}

\section{Obtenção do solo/Substrato}

O solo foi coletado às margens da RN 011, cuja região tem predominância de Latossolo Vermelho Amarelo. A escolha do local deu-se em razão de ser uma jazida de retirada de cascalho ativa, entretanto o "solo" utilizado no experimento na verdade não é solo, e sim um substrato, ou seja, parte do horizonte $\mathrm{C}$ da jazida que fui retirado o cascalho, onde já iria ser iniciado o processo de recuperação. Por ocasião da coleta, inicialmente, realizou-se a limpeza da área com auxílio de uma pá, o material foi acondicionadas em sacos de plásticos e levada ao Laboratório de Biotecnologia-UFERSA, seco ao ar, homogeneizado e peneirado em peneira com $2 \mathrm{~mm}$ de malha, na sequencia retirada uma amostra na qual foram determinados o $\mathrm{pH}$ (solo:água, relação 1:2,5) e $\mathrm{Fe}, \mathrm{Zn}, \mathrm{Mn}, \mathrm{Cu}, \mathrm{Cd}$ e $\mathrm{Pb}$ (Tabela 1), segundo a metodologia recomendada por EMBRAPA (2011).

\section{Obtenção da cinza}

As cinzas foram obtidas em duas indústrias cerâmicas da região do Vale do Açú/RN, sendo acondicionadas em sacos plásticos e trazidas ao laboratório de biotecnologia da UFERSA, onde foram homogeneizadas e retirada uma amostra, na qual foram determinados o $\mathrm{pH}$ (solo:água, relação 1:2,5), além de $\mathrm{Fe}, \mathrm{Zn}, \mathrm{Mn}, \mathrm{Cu}, \mathrm{Cd}$ e $\mathrm{Pb}$ (Tabela 1).. Segundo informações cedidas pelos empresários desse setor, a cinza é proveniente da queima de material vegetal que abrange a espécie invasora algarobeira (Prosopis juliflora) e a poda de cajueiro (Anacardium occidentale), que é uma planta nativa da Caatinga.

\section{Condução do experimento em casa de vegetação}

O experimento foi conduzido em delineamento experimental com esquema fatorial de $5 \times 5$, sendo cinco doses do composto de aguapé e cinco doses de cinza com três repetições, onde o volume de solo correspondeu a $2 \mathrm{dm}^{3}$ e as doses de cinza corresponderam à $0,1,3,5$ e $10 \%$ do volume de cada vaso e às de composto de aguapé à $0,5,10,20$ e 30\%. Após a mistura da composição solo, composto e cinza equivalente a cada tratamento, esta foi colocada em vasos plásticos, incubados 20 dias e em seguida realizado o transplantio das mudas de Jucá (Libidibia ferrea). 
As mudas de Jucá (Libidibia ferrea), após escarificadas utilizando-se lixa d'água no 100 , foram produzidas em bandejas de poliestireno expandido de 128 células, utilizando-se o substrato à base de fibra de coco, sendo o transplantio realizado dez dias após a semeadura e o estande corrigido através do replantio das mudas cinco dias após.

\section{Coleta de dados}

Por ocasião da coleta, após 60 dias as plantas foram cortadas ao nível do solo, acondicionadas em sacos de papel, secas em estufa de circulação forçada de ar a $70^{\circ} \mathrm{C}$ até peso constante, pesadas para obtenção da matéria seca da parte aérea (MSPA), trituradas em moinho tipo Wiley (Figura 6C) e posteriormente foram mineralizadas por digestão nítrica. Nos extratos foram determinados os teores totais de $\mathrm{Fe}, \mathrm{Zn}, \mathrm{Mn}, \mathrm{Cu}, \mathrm{Cd}$ e $\mathrm{Pb}$ (EMBRAPA, 2011).

Após a retirada das plantas, o solo de cada vaso foi seco ao ar, homogeneizado, passado em peneira de $2 \mathrm{~mm}$ de malha e uma amostra foi retirada, para realização das analises de $\mathrm{Fe}, \mathrm{Zn}$, $\mathrm{Mn}, \mathrm{Cu}, \mathrm{Cd}$ e $\mathrm{Pb}$ (EMBRAPA, 2011).

\section{Análise dos Dados}

Para avaliar a absorção de metais pesados pelas plantas em função das doses de cinza e composto, foi utilizado o modelo proposto por Maia et al. (2009), de acordo com a equação 1:

$$
\mathrm{A}=\frac{\mathrm{A}_{\max }}{1+(\dot{a} \cdot) \mathrm{d}^{\mathrm{n}}}
$$

Em que: A é a absorção de metais pelas plantas no tempo t;

$A_{\max }$ é a absorção máxima estimada de metais pelas plantas no tempo $t$; $\alpha$ e $n$ são parâmetros do modelo ajustados por metodologia de regressão não linear.

A dose onde ocorre a taxa de absorção máxima $\left(\mathrm{D}^{\mathrm{T}} \mathrm{TA}_{\max }\right)$ foi calculado pela equação 2, enquanto para estimar a dose que as plantas absorvem $50 \%$ da máxima absorção estimada (D. $A_{\max 50 \%}$ ), utilizou-se a equação 3. Para calcular a taxa de absorção em função das doses $\left(\mathrm{TA}_{\max }\right)$ para uma fração de $A_{\max }(n)$, utilizou-se a equação 4.

D.TA ${ }_{\text {max }}=\frac{1}{a} *\left(\frac{n-1}{n+1}\right)^{1 / n}$
D. $A_{\text {max } 50 \%}=\frac{1}{a ́}$
$\mathbb{A}_{\text {max }}=\frac{A_{\text {max }} \cdot \mathrm{n} \cdot \dot{a}^{\mathrm{n}} \cdot \mathrm{D}^{\mathrm{n}-1}}{\left[1+(\mathrm{a} \cdot) \mathrm{D}^{\mathrm{n}}\right]^{2}}$ 


\section{Resultados e Discussão}

\section{PH e disponibilidade de metais no solo}

Verificou-se acréscimo nos valores de $\mathrm{pH}$ do solo com a adição do composto e da cinza, entretanto tem-se que para uma mesma dose de cinza, o acréscimo no valor de $\mathrm{pH}$ é maior para as doses de 0, 5 e 10\% de composto. Já em relação à cinza, quanto maior a dose, maior o valor do pH (Tabela 2). Darolt, Blanco Neto e Zambon (1993), concluíram que as elevações de pH com a adição de cinza ao solo podem ser atribuídas principalmente pela liberação de carbonato de potássio pela reação da cinza no solo. Em pesquisas realizadas com esterco bovino, biofertilizante e aguapé Silva et al., (2011) e Calgaro et al., (2008), concluíram que a matéria orgânica (MO) também pode contribuir para o aumento do $\mathrm{pH}$ do solo.

\section{Tabela 2 - pH e disponibilidade de metais no solo em função das} doses de cinza e composto

\begin{tabular}{|c|c|c|c|c|c|c|c|c|}
\hline Cinza & Composto & $\mathrm{pH}$ & $\mathbf{F e}$ & Mn & $\mathrm{Cu}$ & $Z_{n}$ & $\mathrm{Cd}$ & $\mathbf{P b}$ \\
\hline$\%$ & $\%$ & & -----. & ------ & $--\mathbf{m g}$ & $n^{-3}--$ & & \\
\hline 0 & 0 & 6,88 & 14,17 & 1,90 & 0,01 & 2,48 & 0,00 & 0,46 \\
\hline 0 & 5 & 8,25 & 7,83 & 5,06 & 0,01 & 2,23 & 0,00 & 0,32 \\
\hline 0 & 10 & 8,23 & 6,83 & 6,46 & 0,01 & 3,05 & 0,00 & 0,27 \\
\hline 0 & 20 & 8,27 & 11,33 & 14,83 & 0,01 & 4,66 & 0,00 & 0,27 \\
\hline 0 & 30 & 8,17 & 7,67 & 19,11 & 0,01 & 5,44 & 0,00 & 0,26 \\
\hline 1 & 0 & 9,03 & 12,00 & 4,56 & 0,03 & 1,51 & 0,00 & 0,42 \\
\hline 1 & 5 & $\begin{array}{l}8,87 \\
072\end{array}$ & 11,00 & 9,98 & 0,02 & 2,29 & 0,00 & 0,33 \\
\hline 1 & 10 & 8,73 & 8,50 & 12,97 & 0,01 & 3,12 & 0,00 & 0,28 \\
\hline 1 & 20 & 8,48 & 4,83 & 18,12 & 0,02 & 4,26 & 0,00 & 0,31 \\
\hline 1 & 30 & 8,20 & 2,83 & 14,12 & 0,01 & 3,75 & 0,00 & 0,25 \\
\hline 3 & 0 & $\begin{array}{l}9,87 \\
0\end{array}$ & 3,33 & 10,53 & 0,03 & 0,44 & 0,00 & 0,31 \\
\hline 3 & 5 & 9,45 & 2,00 & 10,39 & 0,01 & 0,00 & 0,00 & 0,30 \\
\hline 3 & 10 & 8,62 & 0,35 & 7,25 & 0,00 & 0,00 & 0,00 & 0,25 \\
\hline 3 & 20 & 9,31 & 2,17 & 13,02 & 0,01 & 0,00 & 0,00 & 0,24 \\
\hline 3 & 30 & 8,75 & 0,98 & 12,25 & 0,00 & 0,00 & 0,00 & 0,20 \\
\hline 5 & 0 & $\begin{array}{r}10,15 \\
\end{array}$ & 1,15 & 7,03 & 0,01 & 0,00 & 0,00 & 0,19 \\
\hline 5 & 5 & $\begin{array}{l}9,88 \\
0,50\end{array}$ & 1,48 & 8,32 & 0,01 & 0,00 & 0,00 & 0,24 \\
\hline 5 & 10 & $\begin{array}{l}9,58 \\
927\end{array}$ & 0,80 & 8,48 & 0,00 & 0,00 & 0,00 & 0,26 \\
\hline 5 & 20 & $\begin{array}{l}9,37 \\
0.15\end{array}$ & 0,63 & 6,13 & 0,00 & 0,00 & 0,00 & 0,20 \\
\hline 5 & 30 & $\begin{array}{r}9,15 \\
\end{array}$ & 0,58 & 5,96 & 0,00 & 0,00 & 0,00 & 0,22 \\
\hline 10 & 0 & 10,30 & 0,22 & 1,81 & 0,00 & 0,00 & 0,00 & 0,20 \\
\hline 10 & 5 & 10,10 & 0,27 & 3,04 & 0,00 & 0,00 & 0,00 & 0,21 \\
\hline 10 & 10 & 10,09 & 0,17 & 1,43 & 0,00 & 0,00 & 0,00 & 0,21 \\
\hline 10 & 20 & 9,95 & 0,22 & 1,32 & 0,00 & 0,00 & 0,00 & 0,28 \\
\hline 10 & 30 & 9,68 & 0,23 & 1,89 & 0,00 & 0,00 & 0,00 & 0,25 \\
\hline
\end{tabular}

Fonte: Dados da Pesquisa (2015).

No tratamento testemunha verificou-se baixa variação do $\mathrm{pH}$ do solo, de 6,20 (Tabela 1) antes da condução do experimento para 6,88 (Tabela 2) com o término do mesmo. Essa variação pode ter ocorrido em virtude da qualidade da água de irrigação durante o período em que o experimento foi conduzido. 
Com a adição de cinza houve redução nas concentrações da maioria dos metais no solo, inclusive do $\mathrm{Zn}$, que só foi quantificado até a adição de $1 \%$ de cinza. Para o $\mathrm{Cu}$ e $\mathrm{Cd}$ não houve quantificação em nenhum dos tratamentos (Tabela 2). Segundo Sousa, Miranda e Oliveira (2007), a disponibilidade de $\mathrm{Fe}, \mathrm{Mn}, \mathrm{Cu}$ e $\mathrm{Zn}$ diminuem com a elevação do $\mathrm{pH}$ do solo. Uma possível razão para esse decréscimo é que a mobilidade dos metais pesados no solo diminui com o aumento do $\mathrm{pH}$, em virtude da precipitação de formas insolúveis desses elementos, como hidróxidos, carbonatos e complexos orgânicos (NACHTIGALL; NOGUEIROL; ALLEONI, 2009).

Ao variar as doses de composto, observa-se que o $\mathrm{Fe}$ e o $\mathrm{Pb}$ apresentaram maiores concentrações nas doses iniciais ( 0 e $5 \%$ ), sendo que para o $\mathrm{Pb}$, essas variações na concentração foram pouco significativas. Já o $\mathrm{Zn}$ e o Mn apresentaram maiores concentrações nas doses finais (20 e 30\%) de composto e para Cu e Cd não houve quantificação em nenhum dos tratamentos (Tabela 1). Segundo Abreu, Lopes e Santos (2007), o Fe pode estar presente no solo numa forma mais solúvel $\left(\mathrm{Fe}^{2+}\right)$ e outra de menor solubilidade $\left(\mathrm{Fe}^{3+}\right)$. Devido à hidrólise de $\mathrm{Fe}^{3+}$, outras espécies iônicas desse elemento predominam na faixa de $\mathrm{pH}$ entre 5 e 9 . Assim, sua solubilidade decresce em proporções significativamente maiores do que a de elementos como $\mathrm{Mn}, \mathrm{Cu}$ ou $\mathrm{Zn}$.

Sobre o aumento da disponibilidade do Mn, Abreu, Lopes e Santos (2007) explicam que ocorrem frequentemente no solo reações de oxirredução e isso influencia na disponibilidade de micronutrientes no mesmo, com destaque para o Fe e o $\mathrm{Mn}$, os autores concluem que em solos drenados e arejados, o potencial de oxirredução é bastante elevado e em solos inundados, esse potencial cai significativamente, porém, o potencial de oxirredução do $\mathrm{Mn}$ de $\mathrm{Mn}^{4+}$ para $\mathrm{Mn}^{2+}$ ocorre tanto em condições de solo drenado quanto inundado, isso explica porque, mesmo em solos não inundados, a toxidez de Mn é frequente.

Variando as doses de composto houve ajuste dos dados ao modelo para a concentração de Fe no solo quando foi adicionado $1 \%$ de cinza e para o Mn quando não houve adição de cinza (Figura 1A e 1B). Quando houve variação de doses de cinza, tem-se resposta apenas para Mn com adição de 20 e $30 \%$ de composto (Figura 2). Essas informações podem ser confirmadas a partir da observação dos gráficos, onde se percebe valores bastante variados para as diferentes doses, dificultando o ajuste ao modelo.

\section{Figura 1 - Concentração de Fe (A) e Mn (B) no solo em função de doses de composto para diferentes doses de cinza}

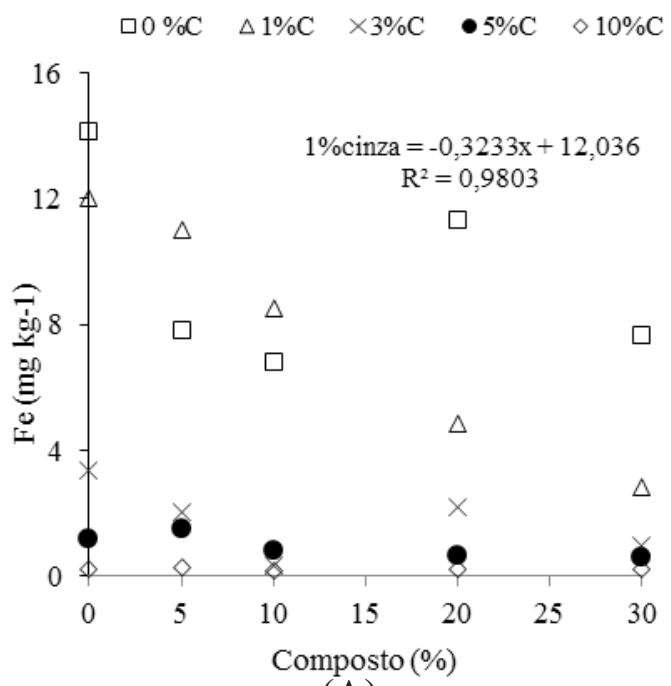

(A)

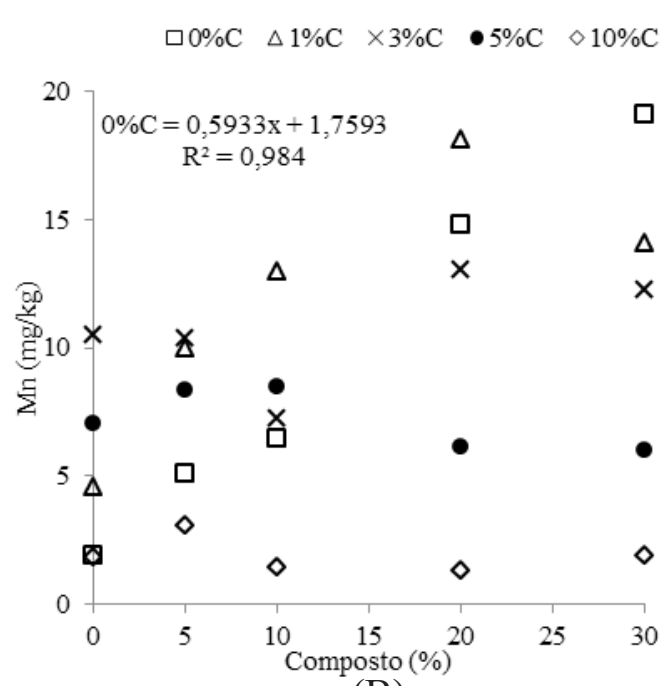

(B)

Fonte: Dados da Pesquisa (2015). 


\section{Figura 2 - Concentração de Mn no solo em função de doses de cinza para diferentes doses de composto}

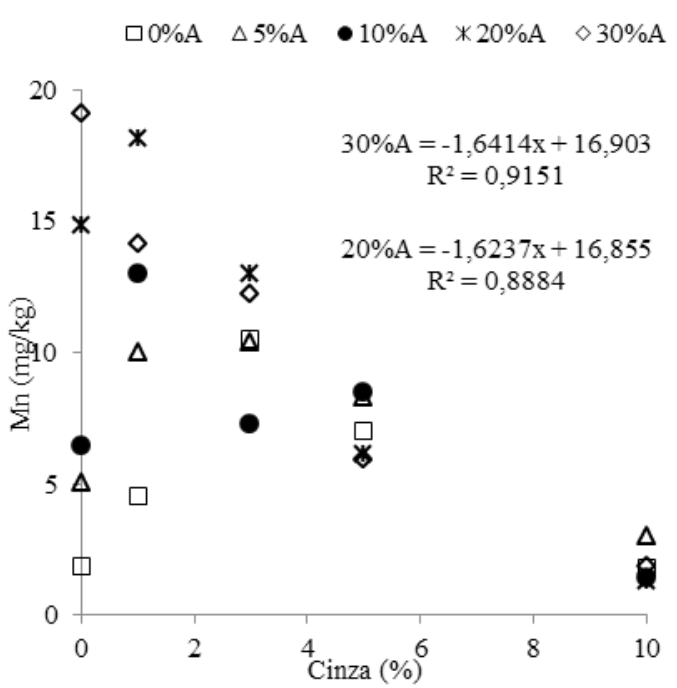

Fonte: Dados da Pesquisa (2015).

\section{Produção de matéria seca e absorção de metais pesados pelas plantas de Jucá}

A produção de MSPA aumentou com o aumento das doses de composto e diminuiu a partir da elevação das doses de cinza. A absorção Fe, Mn, Cu e Zn diminuem para uma mesma dose de cinza e aumento das doses de aguapé (Tabela 3). Em relação às doses de cinza, é possível perceber que, para o Fe os valores são crescentes até a terceira dose, em seguida decrescem; para o $\mathrm{Mn}$ e o $\mathrm{Cu}$, os valores sobem até a segunda dose depois voltam a diminuir. Para o $\mathrm{Cu}$ o valor diminui, mas volta a aumentar na dose máxima de cinza, porém trata-se de um aumento pouco significativo. Para o $\mathrm{Zn}$ e $\mathrm{Pb}$, houve aumento da absorção com o aumento das doses de cinza (Tabela 3).

Para Fe, $\mathrm{Mn}$ e $\mathrm{Cu}$ absorvido pelas plantas, verificou-se valores decrescentes, possivelmente porque a partir da terceira dose de cinza e também das doses crescentes de composto, as plantas começaram a apresentar taxas de mortalidade também crescentes, motivadas possivelmente pelo aumento do $\mathrm{pH}$ do solo. 


\section{Tabela 3 - Matéria seca e concentração de metais nas mudas de Jucá em função de cinza e composto}

\begin{tabular}{|c|c|c|c|c|c|c|c|c|}
\hline Cinza & Composto & MSPA & $\mathbf{F e}$ & Mn & $\mathrm{Cu}$ & $\mathrm{Zn}$ & $\mathrm{Cd}$ & $\mathbf{P b}$ \\
\hline$\%$ & $\%$ & 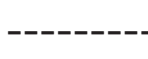 & & 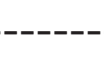 & mg vas & & & \\
\hline 0 & 0 & 0,19 & 0,339 & 0,295 & 0,018 & 0,067 & 0,001 & 0,011 \\
\hline 0 & 5 & 0,40 & 0,299 & 0,060 & 0,019 & 0,032 & 0,001 & 0,011 \\
\hline 0 & 10 & 0,85 & 0,000 & 0,000 & 0,000 & 0,000 & 0,000 & 0,000 \\
\hline 0 & 20 & 2,31 & 0,000 & 0,000 & 0,000 & 0,000 & 0,000 & 0,000 \\
\hline 0 & 30 & 4,02 & 0,000 & 0,000 & 0,000 & 0,000 & 0,000 & 0,000 \\
\hline 1 & 0 & 0,19 & 0,397 & 0,087 & 0,027 & 0,052 & 0,001 & 0,006 \\
\hline 1 & 5 & 0,66 & 0,333 & 0,060 & 0,021 & 0,035 & 0,001 & 0,009 \\
\hline 1 & 10 & 0,95 & 0,139 & 0,030 & 0,012 & 0,020 & 0,001 & 0,010 \\
\hline 1 & 20 & 1,51 & 0,027 & 0,003 & 0,002 & 0,004 & 0,000 & 0,002 \\
\hline 1 & 30 & 4,17 & 0,000 & 0,000 & 0,000 & 0,000 & 0,000 & 0,000 \\
\hline 3 & 0 & 0,00 & 0,517 & 0,093 & 0,038 & 0,072 & 0,001 & 0,009 \\
\hline 3 & 5 & 0,29 & 0,353 & 0,075 & 0,023 & 0,038 & 0,001 & 0,012 \\
\hline 3 & 10 & 1,09 & 0,118 & 0,023 & 0,010 & 0,016 & 0,001 & 0,008 \\
\hline 3 & 20 & 2,06 & 0,000 & 0,000 & 0,000 & 0,000 & 0,000 & 0,000 \\
\hline 3 & 30 & 3,81 & 0,000 & 0,000 & 0,000 & 0,000 & 0,000 & 0,000 \\
\hline 5 & 0 & 0,14 & 0,532 & 0,109 & 0,043 & 0,076 & 0,001 & 0,017 \\
\hline 5 & 5 & 0,43 & 0,198 & 0,048 & 0,012 & 0,045 & 0,001 & 0,012 \\
\hline 5 & 10 & 0,70 & 0,091 & 0,018 & 0,008 & 0,014 & 0,001 & 0,006 \\
\hline 5 & 20 & 1,87 & 0,036 & 0,004 & 0,003 & 0,006 & 0,000 & 0,002 \\
\hline 5 & 30 & 2,69 & 0,000 & 0,000 & 0,000 & 0,000 & 0,000 & 0,000 \\
\hline 10 & 0 & 0,00 & 0,616 & 0,122 & 0,048 & 0,111 & 0,002 & 0,026 \\
\hline 10 & 5 & 0,00 & 0,254 & 0,064 & 0,026 & 0,051 & 0,002 & 0,020 \\
\hline 10 & 10 & 0,31 & 0,061 & 0,011 & 0,004 & 0,013 & 0,000 & 0,004 \\
\hline 10 & 20 & 1,71 & 0,000 & 0,000 & 0,000 & 0,000 & 0,000 & 0,000 \\
\hline 10 & 30 & 1,94 & 0,033 & 0,003 & 0,003 & 0,007 & 0,000 & 0,002 \\
\hline
\end{tabular}

Fonte: Dados da Pesquisa (2015).

As concentrações crescentes de $\mathrm{Pb}$ na planta com o aumento das doses de cinza explicam-se porque na cinza foi possível constatar valores elevados desse metal, ou seja, valores em torno de $30 \mathrm{mg} \mathrm{kg}^{-1}$. O mesmo não pode se justificar para o $\mathrm{Zn}$, uma vez que não foi possível quantificar esse elemento nem na cinza nem no solo ou no composto previamente à montagem do experimento. Sobre o $\mathrm{Zn}$, portanto, essas pequenas alterações na absorção pela planta podem ter sido influenciadas pelo modo como o $\mathrm{Zn}$ poderia estar disponível no solo, no composto ou na cinza, ou seja, o Zn poderia não estar disponível numa forma que o extrator pudesse identificar.

Conforme mencionado anteriormente, o $\mathrm{pH}$ no solo após o cultivo, aumentou a partir da incorporação de doses crescentes de composto e principalmente de cinza. A respeito dos fatores que influenciam na disponibilidade de micronutrientes para as plantas, Abreu, Lopes e Santos (2007) afirmam que o pH do solo é um dos mais relevantes na alteração da disponibilidade de certos elementos, visto que o aumento do $\mathrm{pH}$ diminui a presença dos micronutrientes $\mathrm{Fe}, \mathrm{Mn}, \mathrm{Cu}$ e $\mathrm{Zn}$, reduzindo sua solubilidade no solo e, consequentemente sua disponibilidade para as plantas.

Para os tratamentos com adição de composto, os dados não se ajustaram ao modelo (Figura 3), entretanto, o modelo se ajustou aos dados das características avaliadas para os tratamentos onde se adicionou cinza (Figura 4), com coeficientes de determinação para todas as regressões 
maiores que 0,98 (Tabela 4). O valor estimado para absorção máxima $\left(\mathrm{A}_{\max }\right)$ do $\mathrm{Fe}$ foi superior aos demais, com valor máximo de absorção de 0,48\%, mesmo comportamento para a taxa de absorção máxima $\left(\mathrm{TA}_{\max }\right)$. Em relação à dose para a taxa de absorção máxima (DTA ${ }_{\max }$ ), esta foi maior para o Cd, com a absorção de 2,649\%, a taxa foi mais lenta para o $\mathrm{Zn}$, com absorção de 0,290\% (Tabela 3).

Tabela 4 - Parâmetros ajustados do modelo ( $A_{\max }$, a e $n$ ), coeficiente de determinação $\left(\mathbf{R}^{2}\right)$, dose que as plantas absorvem $50 \%$ da máxima absorção estimada (DA ${ }_{\max 50 \%}$ ), dose para taxa de absorção máxima (DTA ${ }_{\max }$ ) e taxa de absorção máxima $\left(\mathrm{TA}_{\max }\right)$, para os tratamentos com diferentes doses de cinza

\begin{tabular}{cccccccc}
\hline & $\mathbf{M S P A}$ & $\mathbf{F e}$ & $\mathbf{M n}$ & $\mathbf{C u}$ & $\mathbf{Z n}$ & $\mathbf{C d}$ & $\mathbf{P b}$ \\
\cline { 2 - 8 } $\mathrm{A}_{\max }(\%)$ & 3,32 & 0,48 & 0,14 & 0,03 & 0,08 & 0,00 & 0,01 \\
$\mathbf{\alpha}$ & 0,78 & 0,78 & 1,16 & 0,78 & 0,91 & 0,32 & 0,34 \\
$\mathrm{n}$ & 1,22 & 1,62 & 1,59 & 1,44 & 1,38 & 3,42 & 2,53 \\
$\mathrm{R}^{2}$ & 1,00 & 1,00 & 1,00 & 0,99 & 0,99 & 0,98 & 0,98 \\
$\mathrm{DA}_{\max 50 \%}$ & 1,278 & 1,280 & 0,861 & 1,278 & 1,094 & 3,159 & 2,910 \\
$\mathrm{DTA}_{\max }$ & 0,189 & 0,526 & 0,340 & 0,390 & 0,290 & 2,649 & 2,092 \\
$\mathrm{TA}_{\max }$ & 1,735 & 0,229 & 0,100 & 0,017 & 0,043 & 0,000 & 0,004 \\
\hline
\end{tabular}

Fonte: Dados da Pesquisa (2015).

Figura 3 - Matéria seca da parte aérea e concentração de metais pesados em mudas de jucá em função das doses de composto

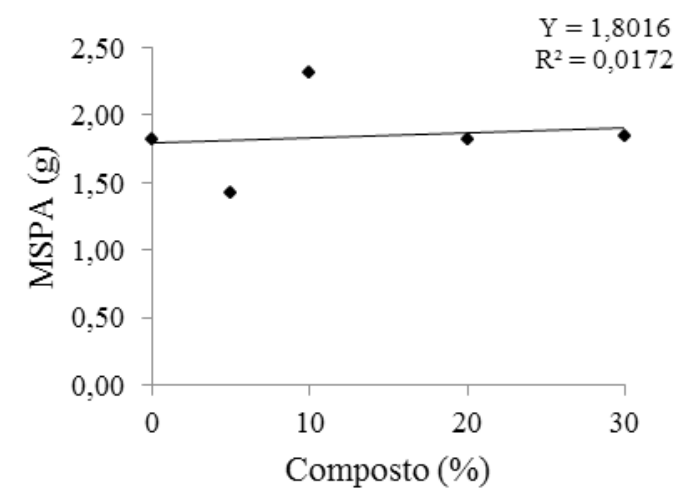

(A)

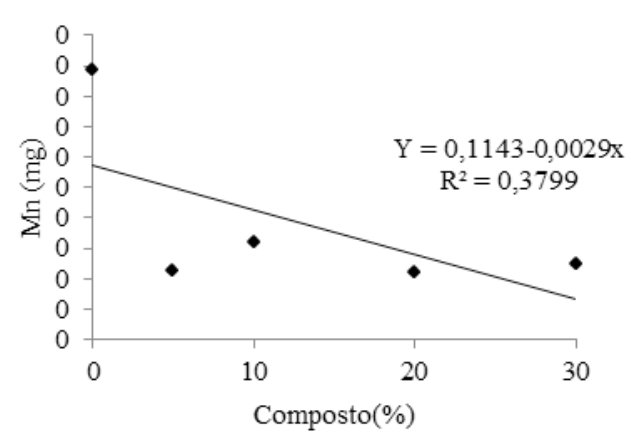

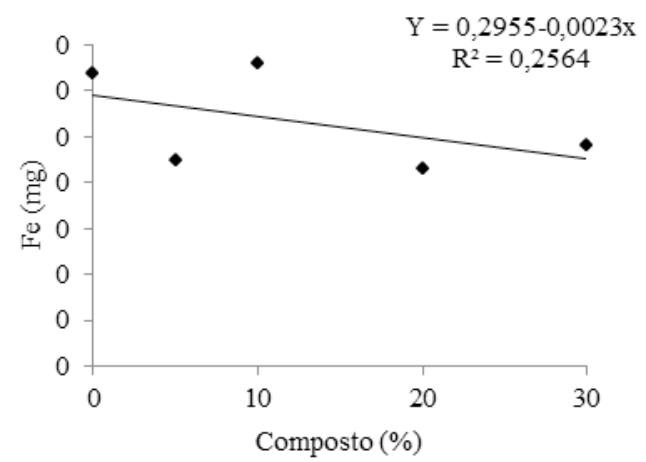

(B)

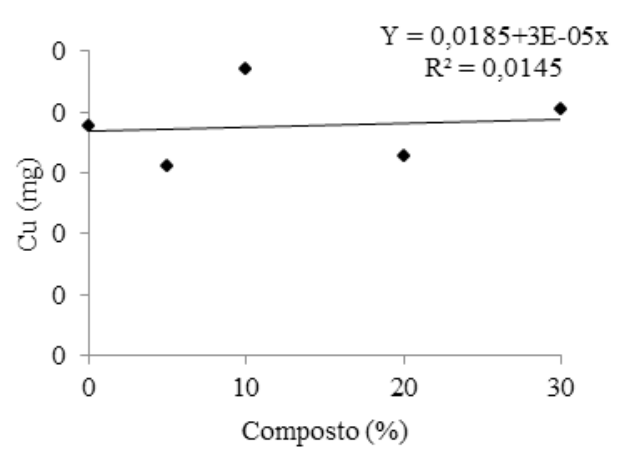


(C)

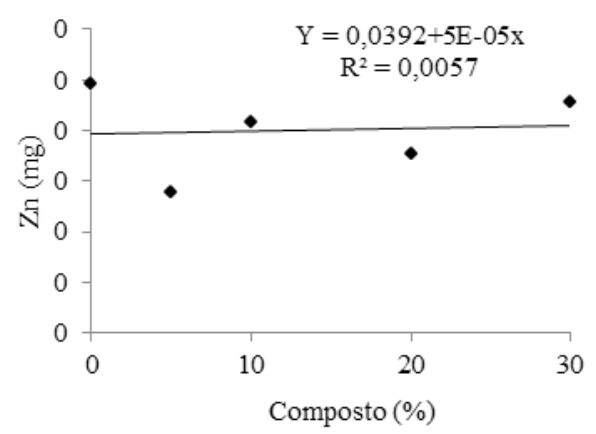

(E)
(D)

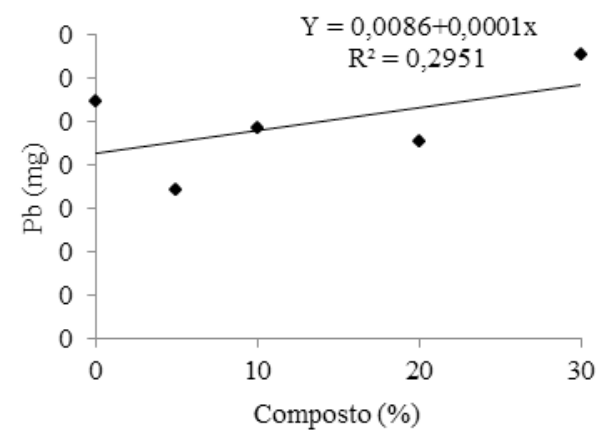

(F)

Fonte: Dados da Pesquisa (2015).

Figura 4 - Matéria seca da parte aérea e concentração de metais pesados em mudas de jucá em função das doses de cinza

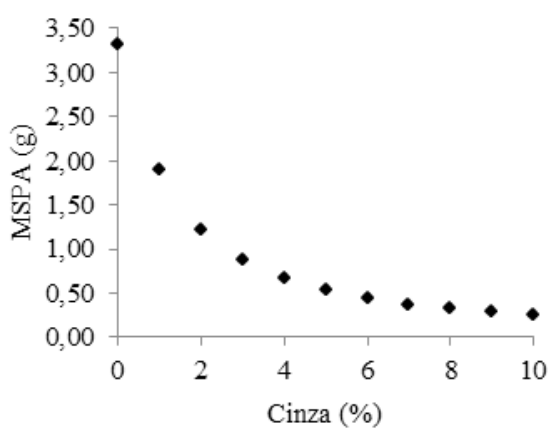

(A)

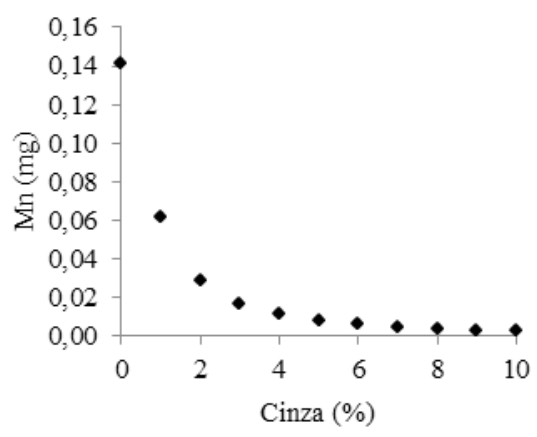

(C)

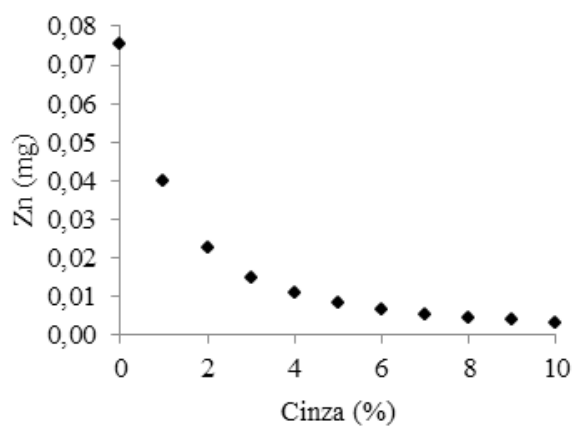

(E)

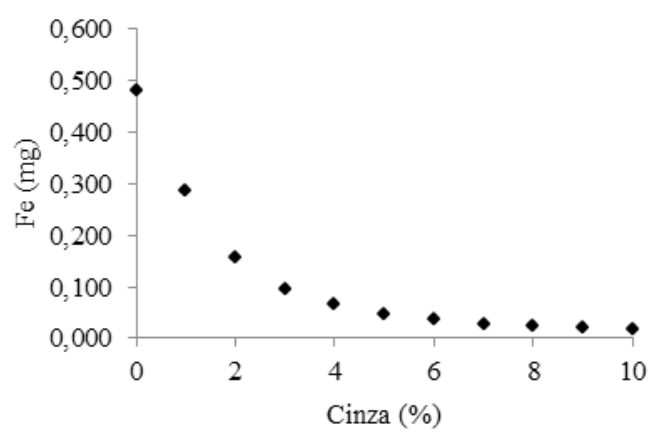

(B)

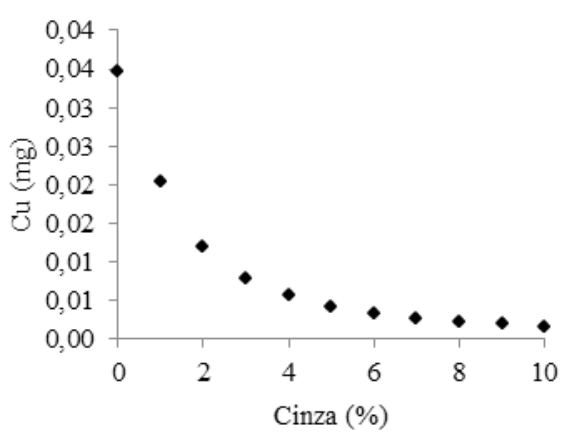

(D)

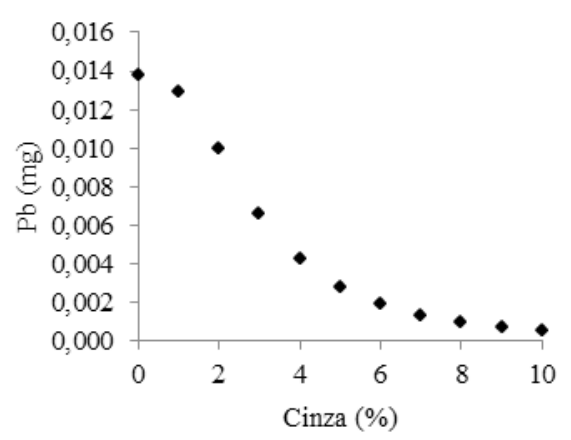

(F)

Fonte: Dados da Pesquisa (2015). 


\section{Conclusão}

Com base na pesquisa realizada, foi possível concluir que:

Com o aumento das doses de cinza verificou-se aumento do $\mathrm{pH}$ no solo/substrato;

O uso da cinza associado ao composto inibiu a disponibilidade de metais pesados no solo/ substrato e absorção pelas plantas;

O modelo matemático estimou satisfatoriamente a absorção máxima de metais pesados pelas mudas e disponibilidade desses elementos no solo em função das doses de cinza e composto de aguapé.

\section{Referências}

ABREU, C. A.; LOPES, A. S.; SANTOS, G. C. G. Micronutrientes. In: NOVAIS, R. F. et al., Fertilidade do solo. Viçosa, MG: SBCS, 2007. cap. 11, p. 645-736.

BONFIM-SILVA, E. M.et al. Cinza vegetal: características produtivas e teor de clorofila do capim-marandu. Biosci.J., Uberlândia, v. 29, n. 5, p. 1215-1225, set./out.2013. Disponível em: <www.seer.ufu.br/index.php/biosciencejournal/ article/download/.../13015>. Acesso em: 25 ago. 2014.

CALGARO, H. F. et al. Resíduos orgânicos como recondicionante de subsolo degradado e efeitos na atividade microbiana e fertilidade em cultivo de Barbatimão. R. Árvore, Viçosa, MG, v. 32, n. 6, p. 1069-1079, 2008. Disponível em: <http://www.scielo.br/pdf/ rarv/v32n6/ a12v32n6.pdf>. Acesso em: 18 set. 2014.

DAROLT, M. R.; BLANCO NETO, V.; ZAMBON, F. R.A. Cinza vegetal como fonte de nutrientes e corretivo de solo na cultura de alface. Hort. Bras., v. 11, n. 1, p. 38-40, maio 1993. Disponível em: <http://www.iapar.br/arquivos/File/zip_pdf/ darolt_cinzavegetal. pdf>. Acesso em: 12 ago. 2014.

EMBRAPA - EMPRESA BRASILEIRA DE PESQUISA AGROPECUÁRIA. Manual de métodos de análise de solo. Rio de Janeiro: EMBRAPA, 2011. Disponível em: <http://www.infoteca.cnptia.embrapa.br/bitstream/doc/990374/1/ ManualdeMtodosdeAnilisedeSolo.pdf>. Acesso em: 19 abr. 2014.

GRIGIO, A. M.; DIODATO, M. A. Dimensões físico-ambiental. In: PESSOA, Z. S. et al. (Org.). Como anda Mossoró: análise da conjuntura sociourbana. Natal: UFRN, 2011. cap. 4.

IBGE - INSTITUTO BRASILEIRO DE GEOGRAFIA E ESTATÍSTICA. IBGE Cidades: Rio Grande do Norte: Mossoró, 2010. Disponível em: <http://www.ibge.gov. br/cidadesat/ topwindow.htm?1>. Acesso em: 30 set. 2014. 
IDEMA - INSTITUTO DE DESENVOLVIMENTO SUSTENTÁVEL E MEIO AMBIENTE DO RIO GRANDE DO NORTE. Licenciamento ambiental: competência para licenciar. 2014. Disponível em: <http://www.idema.rn.gov.br/ Conteu do.p?TRAN=ITEM \&TARG $=2114 \& A C T=\& P A G E=0 \& P A R M=\& L B L=$ Licenciame nto+Ambiental>. Acesso em: 29 set. 2014.

MAEDA, S.; SILVA, H.D.; MAGALHÃES, W.L. E. Caracterização química de cinza de biomassa vegetal e respostas à sua aplicação em Latossolo e Cambissolo de Piraí do Sul,PR. Colombo: Embrapa Florestas, 2007. Disponível em: <http://www.infoteca.cnptia. embrapa.br/infoteca/bitstream/doc/314054/1/Doc155.pdf>. Acesso em 22 ago. 2014.

MAIA, C. E. et al. Crescimento do meloeiro Orange flesh em função do preparo do solo e construção de camalhão. Revista Ciência Agronômica, v. 40, n. 1, p. 41-47, 2009. Disponível em: < http://ccarevista.ufc.br/seer/index.php/ccarevista/article/view/401>. Acesso em: 22 dez. 2015.

MALAVOLTA, E. et al. Sobre a composição mineral do aguapé (Eichhornia crassipes). An. Esalq., v. 46, pt. 1, p. 155-162, 1989. Disponível em: <http://www.scielo.br/pdf/aesalq/ v46n1/11.pdf>. Acesso em: 20 ago. 2014.

NACHTIGALL, G. R.; NOGUEIROL, R. C.; ALLEONI,L. R. F. Extração sequencial de $\mathrm{Mn}$ e $\mathrm{Zn}$ em solos em função do $\mathrm{pH}$ e adição de cama-de-frango. Revista Brasileira de Engenharia Agrícola e Ambiental, v. 13, n. 3, p. 240-249, 2009. Disponível em: <http:// www.scielo.br/pdf/rbeaa/v13n3/v13n03a04.pdf>. Acesso em 27 jan. 2016.

SILVA et al. Avaliação do $\mathrm{pH}$ e do teor de matéria orgânica do solo após colheita do inhame adubado com esterco bovino e biofertilizante. In: CONGRESSO BRASILEIRO DE OLEICULTURA, 51., 2011, Viçosa, Anais..., Viçosa: Hort. Brasileira, 2011. Disponível em: <http://www.abhorticultura.com.br/eventosx/trabalhos/ev_5/ a3891_t5179_comp. pdf>. Acesso em: 01 fev. 2016.

SOUSA, D. M.; MIRANDA, L. N.; OLIVEIRA, S. A. Acidez do solo e sua correção. In: NOVAIS, R. F. et al., Fertilidade do solo. Viçosa, MG: SBCS, 2007. cap. 5, p. 205-274.

TAVARES, S. R. de L. et al. Curso de recuperação de áreas degradadas: a visão da ciência do solo no contexto do diagnóstico, manejo, indicadores de monitoramento e estratégias de recuperação. Rio de Janeiro: Embrapa Solos; Ministério da Agricultura, Pecuária e Abastecimento, 2008. Disponível em: <http://goo.gl/yehHJl>. Acesso em: 22 abr. 2014. 